\title{
Multiple positive solutions of fractional-order boundary value problem with integral boundary conditions
}

\author{
Youyu Wang*, Shuilian Liang, Qichao Wang
}

Department of Mathematics, Tianjin University of Finance and Economics, Tianjin 300222, P. R. China.

Communicated by S. S. Chang

\begin{abstract}
We concentrate on investigating the existence of positive solutions for fractional-order differential equations with integral conditions in this article. The problem is issued by applying Avery-Peterson fixed-point theorem and the properties of Green's function. At the same time, we provide an example to make our results clear and easy for readers' to understand the multiplicity of solutions. (C)2017 All rights reserved.
\end{abstract}

Keywords: Fractional differential equation, integral boundary value conditions, multiplicity of positive solutions. 2010 MSC: 34B15, 34B18.

\section{Introduction}

Fractional differential equations are popular in recent years with their wide application in many fields of science and technology. Since fields of physics, biology, and aerodynamics have a lot to do with the fractional differential equations, many researchers provided different methods to solve practical problems once kept us from moving on. Recently, the fractional-order differential equations with integral boundary value problems have attracted a great deal of attention and interests. The authors used different kinds of fixed point theorems (Krasnoselskii fixed-point theorem, Leray-Schauder fixed-point theorem, LeggettWilliams fixed-point theorem, Avery-Peterson fixed-point theorem) to deal with different equations, see $[1,5-7,10,11]$.

Especially, Ahmada and Nieto investigated the fractional integro-differential equation with integral boundary conditions in paper [2]:

$$
\left\{\begin{array}{l}
{ }^{c} D_{0+}^{q} x(t)=f(t, x(t),(\chi x)(t)), \quad t \in(0,1), \\
\alpha \chi(0)+\beta x^{\prime}(0)=\int_{0}^{1} q_{1}(x(s)) d s \\
\alpha \chi(1)+\beta x^{\prime}(1)=\int_{0}^{1} q_{2}(x(s)) d s
\end{array}\right.
$$

\footnotetext{
*Corresponding author

Email addresses: wang_youyu@163.com (Youyu Wang), sunshinelsl@163.com (Shuilian Liang), qichaowang@163.com (Qichao Wang)
}

doi:10.22436/jnsa.010.12.17 
where $1<\mathrm{q} \leqslant 2,{ }^{\mathrm{c}} \mathrm{D}^{\mathrm{q}}$ is the standard Caputo fractional derivative, and $(\chi x)(t)=\int_{0}^{t} \gamma(\mathrm{t}, \mathrm{s}) \chi(\mathrm{s}) \mathrm{ds}$.

Ding and Pang considered the three nonnegative solutions for fractional differential equations with integral boundary conditions:

$$
\left\{\begin{array}{l}
{ }^{c} D_{0+}^{\alpha} x(t)+f(t, x(t))=0, \quad t \in(0,1) \\
a x(0)-b x^{\prime}(0)=0, c x(1)+d x^{\prime}(1)=0 \\
x^{\prime \prime}(0)+x^{\prime \prime \prime}(0)=\int_{0}^{1} x^{\prime \prime}(\tau) d p(\tau) \\
x^{\prime \prime}(1)+x^{\prime \prime \prime}(1)+\int_{0}^{1} x^{\prime \prime}(\tau) d q(\tau)=0
\end{array}\right.
$$

where $3<\alpha \leqslant 4$ is a real number, $a, b, c, d \geqslant 0, \rho=a d+a c+b c>0 .{ }^{c} D^{\alpha}$ is the Caputo fractional derivative and $f$ satisfies three conditions in [9].

In addition, Boucherif and Zhang considered the existence of positive solutions for the second order differential equation with integral boundary value problem in [4, 12].

Inspired by seniors' wonderful researches, we are focusing on the existence of multiple positive solutions of fractional differential equations with integral boundary value conditions in this article:

$$
\left\{\begin{array}{l}
{ }^{c} D_{0+}^{\alpha} u(t)=f\left(t, u(t), u^{\prime}(t)\right), \quad t \in[0,1] \\
u^{\prime \prime}(0)=0, u^{(3)}(0)=0 \\
u(0)+a u^{\prime}(0)=\int_{0}^{1} g_{1}(s) u(s) d s \\
u(1)-b u^{\prime}(1)=\int_{0}^{1} g_{2}(s) u(s) d s
\end{array}\right.
$$

where $3<\alpha<4, g_{1}(t), g_{2}(t) \in C([0,1],[0,+\infty))$, and $a, b>0$. In addition, ${ }^{c} D^{\alpha}$ denotes the Caputo fractional derivative, and $f:[0,1] \times[0,+\infty) \times(-\infty,+\infty) \rightarrow[0,+\infty)$ is continuous.

To ensure readability of the passage we assume the following conditions hold:

$\left(\mathrm{H}_{1}\right) \quad b \geqslant a \geqslant 1 ;$

$\left(\mathrm{H}_{2}\right) \mathrm{f} \in \mathrm{C}([0,1] \times[0,+\infty) \times(-\infty,+\infty),[0,+\infty)) ;$

$\left(\mathrm{H}_{3}\right) \mathrm{g}_{1}, \mathrm{~g}_{2} \in \mathrm{C}([0,1],[0,+\infty)), 0 \leqslant \sigma_{1}+\sigma_{2}<1, \rho=1-\sigma_{1}-\sigma_{4}+\sigma_{1} \sigma_{4}-\sigma_{2} \sigma_{3}>0$, where

$$
\begin{aligned}
\sigma_{1} & =\int_{0}^{1} \frac{b+s-1}{a+b-1} g_{1}(s) d s, & \sigma_{2} & =\int_{0}^{1} \frac{a-s}{a+b-1} g_{1}(s) d s, \\
\sigma_{3} & =\int_{0}^{1} \frac{b+s-1}{a+b-1} g_{2}(s) d s, & \sigma_{4} & =\int_{0}^{1} \frac{a-s}{a+b-1} g_{2}(s) d s .
\end{aligned}
$$

The paper is organized in four parts. We recall certain important preliminaries as preparations in Section 2. Section 3 is arranged to make out the results of multiplicity positive solutions. And in Section 4 , an example is given to illustrate main results.

\section{Preliminaries}

Definition 2.1. The Riemann-Liouville fractional integral of order $\alpha>0$ for a function $f \in(0, \infty) \rightarrow R$ is defined as

$$
\mathrm{I}_{0^{+}}^{\alpha} \mathrm{f}(\mathrm{t})=\frac{1}{\Gamma(\alpha)} \int_{0}^{\mathrm{t}}(\mathrm{t}-\mathrm{s})^{\alpha-1} \mathrm{f}(\mathrm{s}) \mathrm{ds},
$$

provided the right side is pointwise defined on $(0, \infty)$ where $\Gamma(\cdot)$ is the Gamma function.

Definition 2.2. For a function $f:[0,+\infty) \rightarrow R$ the Captuo derivative of fractional order $\alpha$ is defined as

$$
{ }^{c} D_{0^{+}}^{\alpha} f(t)=\frac{1}{\Gamma(n-\alpha)} \int_{0}^{t}(t-s)^{n-\alpha-1} f^{(n)}(s) d s, \quad n=[\alpha]+1,
$$

where $[\alpha]$ denotes the integer part of the real number $\alpha$. 
Definition 2.3. The Riemann-Liouville fractional derivative of order $\alpha$ for a function $f$ is defined by

$$
D_{0^{+}}^{\alpha} f(t)=\frac{1}{\Gamma(n-\alpha)}\left(\frac{d}{d t}\right)^{n} \int_{0}^{t}(t-s)^{n-\alpha-1} f(s) d s, \quad n=[\alpha]+1,
$$

provided that the right-hand side of the equation is pointwise defined on $(0,+\infty)$.

Lemma 2.4 ([5]). Let $\alpha>0$, then the fractional differential equation

$$
{ }^{c} D^{\alpha} u(t)=0
$$

has a unique solution

$$
u(t)=\sum_{j=0}^{[\alpha]} \frac{u^{(j)}(0)}{j !} t^{j}
$$

Lemma 2.5 ([5]). Let $\alpha>0$, then

$$
I^{\alpha c} D^{\alpha} u(t)=u(t)-\sum_{j=0}^{[\alpha]} \frac{u^{(j)}(0)}{j !} t^{j}
$$

We are ready to find out the exact expression of the Green's function associated with the fractionalorder differential equation with boundary value conditions:

$$
\left\{\begin{array}{l}
{ }^{c} D_{0+}^{\alpha} u(t)=y(t), \quad t \in[0,1], \\
u^{\prime \prime}(0)=0, u^{(3)}(0)=0, \\
u(0)+a u^{\prime}(0)=\int_{0}^{1} g_{1}(s) u(s) d s, \\
u(1)-b u^{\prime}(1)=\int_{0}^{1} g_{2}(s) u(s) d s .
\end{array}\right.
$$

Lemma 2.6. Let $3<\alpha<4$. Assume $\mathrm{y} \in \mathrm{C}[0,1]$ and $\left(\mathrm{H}_{1}\right)$ holds, then the problem (2.1) has a unique solution $\mathrm{u}(\mathrm{t})$ given by the expression

$$
u(t)=\int_{0}^{1} G(t, s) y(s) d s+\int_{0}^{1} R(t, s) \int_{0}^{1} G(s, \tau) y(\tau) d \tau d s
$$

where

$$
G(t, s)= \begin{cases}\frac{(a+b-1)(t-s)^{\alpha-1}+(t-a)(1-s)^{\alpha-1}+b(\alpha-1)(a-t)(1-s)^{\alpha-2}}{(a+b-1) \Gamma(\alpha)}, & 0 \leqslant s \leqslant t \leqslant 1, \\ \frac{(t-a)(1-s)^{\alpha-1}+b(\alpha-1)(a-t)(1-s)^{\alpha-2}}{(a+b-1) \Gamma(\alpha)}, & 0 \leqslant t \leqslant s \leqslant 1,\end{cases}
$$

and

$$
R(t, s)=\frac{\left[(a-t) \sigma_{3}+(t+b-1)\left(1-\sigma_{4}\right)\right] g_{1}(s)+\left[(a-t)\left(1-\sigma_{1}\right)+(t+b-1) \sigma_{2}\right] g_{2}(s)}{\rho(a+b-1)} .
$$

Proof. According to Lemma 2.5, the general solution of fractional differential equation (2.1) can be written as

$$
u(t)=I_{0+}^{\alpha} y(t)+c_{0}+c_{1} t+c_{2} t^{2}+c_{3} t^{3},
$$

where $c_{i} \in R, i=0,1,2,3$, are arbitrary constants. With the condition $u^{\prime \prime}(0)=u^{(3)}(0)=0$, we find that $c_{2}=c_{3}=0$. Substituting $c_{2}$ and $c_{3}$ in the equation (2.2) and using the conditions left in the resulting equation yields a system of equations:

$$
\left\{\begin{array}{l}
c_{0}+a c_{1}=\int_{0}^{1} g_{1}(s) u(s) d s \\
c_{0}+(1-b) c_{1}=\int_{0}^{1} \frac{b(1-s)^{\alpha-2}}{\Gamma(\alpha-1)} y(s) d s-\int_{0}^{1} \frac{(1-s)^{\alpha-1}}{\Gamma(\alpha)} y(s) d s+\int_{0}^{1} g_{2}(s) u(s) d s
\end{array}\right.
$$


Solving the system for $c_{0}$ and $c_{1}$, we get

$$
\begin{aligned}
c_{0}= & \frac{a b}{a+b-1} \int_{0}^{1} \frac{(1-s)^{\alpha-2}}{\Gamma(\alpha-1)} y(s) d s-\frac{a}{a+b-1} \int_{0}^{1} \frac{(1-s)^{\alpha-1}}{\Gamma(\alpha)} y(s) d s \\
& +\frac{b-1}{a+b-1} \int_{0}^{1} g_{1}(s) u(s) d s+\frac{a}{a+b-1} \int_{0}^{1} g_{2}(s) u(s) d s,
\end{aligned}
$$

and

$$
\begin{aligned}
c_{1}= & \frac{1}{a+b-1} \int_{0}^{1} \frac{(1-s)^{\alpha-1}}{\Gamma(\alpha)} y(s) d s-\frac{b}{a+b-1} \int_{0}^{1} \frac{(1-s)^{\alpha-2}}{\Gamma(\alpha-1)} y(s) d s \\
& +\frac{1}{a+b-1} \int_{0}^{1} g_{1}(s) u(s) d s-\frac{1}{a+b-1} \int_{0}^{1} g_{2}(s) u(s) d s .
\end{aligned}
$$

Therefore, we have the form of $u(t)$ as follows:

$$
u(t)=I_{0+}^{\alpha} y(t)+c_{0}+c_{1} t=\int_{0}^{1} G(t, s) y(s) d s+\frac{t+b-1}{a+b-1} \int_{0}^{1} g_{1}(s) u(s) d s+\frac{a-t}{a+b-1} \int_{0}^{1} g_{2}(s) u(s) d s .
$$

For convenience, we can get the exact form of $u(t)$ by solving following equation set:

$$
\begin{aligned}
& \left(1-\sigma_{1}\right) \int_{0}^{1} g_{1}(s) u(s) d s-\sigma_{2} \int_{0}^{1} g_{2}(s) u(s) d s=\int_{0}^{1} g_{1}(s) \int_{0}^{1} G(s, \tau) y(s) d \tau d s, \\
& \left(1-\sigma_{4}\right) \int_{0}^{1} g_{2}(s) u(s) d s-\sigma_{3} \int_{0}^{1} g_{1}(s) u(s) d s=\int_{0}^{1} g_{2}(s) \int_{0}^{1} G(s, \tau) y(s) d \tau d s,
\end{aligned}
$$

and

$$
\begin{aligned}
& \int_{0}^{1} g_{1}(s) u(s) d s=\frac{\left(1-\sigma_{4}\right) \int_{0}^{1} g_{1}(s) \int_{0}^{1} G(s, \tau) y(\tau) d \tau d s+\sigma_{2} \int_{0}^{1} g_{2}(s) \int_{0}^{1} G(s, \tau) y(\tau) d \tau d s}{\left(1-\sigma_{1}\right)\left(1-\sigma_{4}\right)-\sigma_{2} \sigma_{3}}, \\
& \int_{0}^{1} g_{2}(s) u(s) d s=\frac{\sigma_{3} \int_{0}^{1} g_{1}(s) \int_{0}^{1} G(s, \tau) y(\tau) d \tau d s+\left(1-\sigma_{1}\right) \int_{0}^{1} g_{2}(s) \int_{0}^{1} G(s, \tau) y(\tau) d \tau d s}{\left(1-\sigma_{1}\right)\left(1-\sigma_{4}\right)-\sigma_{2} \sigma_{3}} .
\end{aligned}
$$

Finally, we obtain that

$$
u(t)=\int_{0}^{1} G(t, s) y(s) d s+\int_{0}^{1} R(t, s) \int_{0}^{1} G(s, \tau) y(\tau) d \tau d s
$$

where

$$
G(t, s)= \begin{cases}\frac{(a+b-1)(t-s)^{\alpha-1}+(t-a)(1-s)^{\alpha-1}+b(\alpha-1)(a-t)(1-s)^{\alpha-2}}{(a+b-1) \Gamma(\alpha)}, & 0 \leqslant s \leqslant t \leqslant 1 \\ \frac{(t-a)(1-s)^{\alpha-1}+b(\alpha-1)(a-t)(1-s)^{\alpha-2}}{(a+b-1) \Gamma(\alpha)}, & 0 \leqslant t \leqslant s \leqslant 1,\end{cases}
$$

and

$$
R(t, s)=\frac{\left[(a-t) \sigma_{3}+(t+b-1)\left(1-\sigma_{4}\right)\right] g_{1}(s)+\left[(a-t)\left(1-\sigma_{1}\right)+(t+b-1) \sigma_{2}\right] g_{2}(s)}{\rho(a+b-1)}
$$

Lemma 2.7. Fix $3<\alpha<4$, and assume $\left(\mathrm{H}_{1}\right)$ holds. Let $\mathrm{G}(\mathrm{t}, \mathrm{s})$ be the Green function related to problem (2.1) given by the expression above, then we have

$$
(1-t) G(0, s) \leqslant G(t, s) \leqslant G(0, s) .
$$


Proof. Denote $H(t, s)=\frac{G(t, s)}{G(0, s)}$. When $0 \leqslant t \leqslant s \leqslant 1$,

$$
H(t, s)=\frac{b(\alpha-1)(a-t)(1-s)^{\alpha-2}-(a-t)(1-s)^{\alpha-1}}{a b(\alpha-1)(1-s)^{\alpha-2}-a(1-s)^{\alpha-1}}=\frac{a-t}{a}=1-\frac{t}{a} \leqslant 1,
$$

and it is obvious to see that $(1-t) \leqslant H(t, s) \leqslant 1$.

On the other side, when $0 \leqslant s \leqslant t \leqslant 1$,

$$
H(t, s)=\frac{(a+b-1)(t-s)^{\alpha-1}+b(\alpha-1)(a-t)(1-s)^{\alpha-2}-(a-t)(1-s)^{\alpha-1}}{a b(\alpha-1)(1-s)^{\alpha-2}-a(1-s)^{\alpha-1}},
$$

the equality can be simplified as

$$
H(t, s)=\frac{(a+b-1)(t-s)^{\alpha-1}}{a b(\alpha-1)(1-s)^{\alpha-2}-a(1-s)^{\alpha-1}}+\left(1-\frac{t}{a}\right),
$$

so it is easy to find out $\mathrm{H}(\mathrm{t}, \mathrm{s}) \geqslant(1-\mathrm{t})$.

When differentiate twice $H(t, s)$ with respect to $t$,

$$
\frac{\partial^{2} H(t, s)}{\partial t^{2}}=\frac{(\alpha-1)(\alpha-2)(a+b-1)(t-s)^{\alpha-3}}{a b(\alpha-1)(1-s)^{\alpha-2}-a(1-s)^{\alpha-1}} \geqslant 0, \quad 0 \leqslant s \leqslant t \leqslant 1 .
$$

Hence, maximum value of $H(t, s)$ can be obtained at either $t=s$ or $t=1$ as follows

$$
\begin{aligned}
H(s, s) & =\frac{b(\alpha-1)(1-s)^{\alpha-1}-(1-s)^{\alpha}}{a b(\alpha-1)(1-s)^{\alpha-2}-a(1-s)^{\alpha-1}}=1-\frac{s}{a} \leqslant 1, \\
H(1, s) & =\frac{(a+b-1)(1-s)^{\alpha-1}+b(\alpha-1)(a-1)(1-s)^{\alpha-2}-(a-1)(1-s)^{\alpha-1}}{a b(\alpha-1)(1-s)^{\alpha-2}-a(1-s)^{\alpha-1}} \\
& =\frac{a b(\alpha-1)-[b(\alpha-1)-b(1-s)]}{a b(\alpha-1)-a(1-s)} \\
& \leqslant \frac{a b(\alpha-1)-a[(\alpha-1)-(1-s)]}{a b(\alpha-1)-a(1-s)} \leqslant \frac{a b(\alpha-1)-a(1-s)}{a b(\alpha-1)-a(1-s)}=1,
\end{aligned}
$$

so the result that $(1-t) \leqslant H(t, s) \leqslant 1$ also holds while $0 \leqslant s \leqslant t \leqslant 1$.

Therefore, inequalities (2.3) hold.

Definition 2.8 ([8]). Let $E$ be a real Banach space. A nonempty convex closed set $\mathrm{P} \subset \mathrm{E}$ is said to be a cone provided that

(i) $a u \in P$ for all $u \in P$ and all $a \geqslant 0$, and

(ii) $u,-u \in P$ implies $u=0$.

Note that every cone $P \subset E$ includes an ordering in $E$ given by $x \leqslant y$ if $y-x \in P$.

Definition 2.9 ([8]). The map $\varphi$ is defined as a nonnegative continuous concave functional on a cone $\mathrm{P}$ of a real Banach space $\mathrm{E}$ provided that $\varphi: \mathrm{P} \rightarrow[0,+\infty)$ is continuous and

$$
\varphi(t x+(1-t) y) \geqslant t \varphi(x)+(1-t) \varphi(y)
$$

for all $x, y \in P$ and $0 \leqslant t \leqslant 1$. Similarly, we say the map $\beta$ is a nonnegative continuous convex functional on a cone $P$ of a real Banach space $E$ provided that $\beta: P \rightarrow[0,+\infty)$ is continuous and

$$
\beta(t x+(1-t) y) \leqslant t \beta(x)+(1-t) \beta(y)
$$

for all $x, y \in P$ and $0 \leqslant t \leqslant 1$. 
Definition 2.10. An operator is called completely continuous if it is continuous and maps bounded sets into pre-compact sets.

Let $\gamma$ and $\theta$ be nonnegative continuous convex functionals on $\mathrm{P}, \varphi$ be a nonnegative continuous concave functional on $\mathrm{P}$ and $\psi$ be a nonnegative continuous functional on $\mathrm{P}$. Then for positive real numbers $a^{\prime}, b^{\prime}, c^{\prime}$, and $d^{\prime}$, we define the following convex sets

$$
\begin{aligned}
\mathrm{P}\left(\gamma, \mathrm{d}^{\prime}\right) & =\left\{x \in \mathrm{P} \mid \gamma(x)<\mathrm{d}^{\prime}\right\}, \\
\mathrm{P}\left(\gamma, \varphi, \mathrm{b}^{\prime}, \mathrm{d}^{\prime}\right) & =\left\{x \in \mathrm{P} \mid \mathrm{b}^{\prime} \leqslant \varphi(x), \gamma(x) \leqslant \mathrm{d}^{\prime}\right\}, \\
\mathrm{P}\left(\gamma, \theta, \varphi, \mathrm{b}^{\prime}, \mathrm{c}^{\prime}, \mathrm{d}^{\prime}\right) & =\left\{x \in \mathrm{P} \mid \mathrm{b}^{\prime} \leqslant \varphi(x), \theta(x) \leqslant \mathrm{c}^{\prime}, \gamma(x) \leqslant \mathrm{d}^{\prime}\right\},
\end{aligned}
$$

and a closed set

$$
R\left(\gamma, \psi, a^{\prime}, d^{\prime}\right)=\left\{x \in P \mid a^{\prime} \leqslant \psi(x), \gamma(x) \leqslant d^{\prime}\right\} .
$$

Theorem 2.11 ([3]). Let $\mathrm{P}$ be a cone in a real Banach space E. Let $\gamma$ and $\theta$ be nonnegative continuous convex functionals on $\mathrm{P}, \varphi$ be a nonnegative continuous concave functional on $\mathrm{P}$, and $\psi$ be a nonnegative continuous functional on $\mathrm{P}$ satisfying $\psi(\lambda x) \leqslant \lambda \psi(x)$ for $0 \leqslant \lambda \leqslant 1$, such that for some positive numbers $M$ and $\mathrm{d}^{\prime}$,

$$
\varphi(x) \leqslant \psi(x) \text { and }\|x\| \leqslant M \gamma(x)
$$

for all $\mathrm{x} \in \overline{\mathrm{P}\left(\gamma, \mathrm{d}^{\prime}\right)}$. Suppose $\mathrm{T}: \overline{\mathrm{P}\left(\gamma, \mathrm{d}^{\prime}\right)} \rightarrow \overline{\mathrm{P}\left(\gamma, \mathrm{d}^{\prime}\right)}$ is completely continuous and there exist positive numbers $\mathrm{a}^{\prime}, \mathrm{b}^{\prime}$, and $\mathrm{c}^{\prime}$ with $\mathrm{a}^{\prime}<\mathrm{b}^{\prime}$ such that

$\left(\mathrm{S}_{1}\right)\left\{x \in \mathrm{P}\left(\gamma, \theta, \varphi, \mathrm{b}^{\prime}, \mathrm{c}^{\prime}, \mathrm{d}^{\prime}\right) \mid \varphi(\mathrm{x})>\mathrm{b}^{\prime}\right\} \neq \Phi$ and $\varphi(\mathrm{T} x)>\mathrm{b}^{\prime}$ for $\mathrm{x} \in \mathrm{P}\left(\gamma, \theta, \varphi, \mathrm{b}^{\prime}, \mathrm{c}^{\prime}, \mathrm{d}^{\prime}\right)$;

$\left(\mathrm{S}_{2}\right) \varphi(\mathrm{T} x)>\mathrm{b}^{\prime}$ for $\mathrm{x} \in \mathrm{P}\left(\gamma, \varphi, \mathrm{b}^{\prime}, \mathrm{d}^{\prime}\right)$ with $\theta(\mathrm{T} x)>\mathrm{c}^{\prime}$;

$\left(\mathrm{S}_{3}\right) 0 \notin \mathrm{R}\left(\gamma, \psi, \mathrm{a}^{\prime}, \mathrm{d}^{\prime}\right)$ and $\psi(\mathrm{T} x)<\mathrm{a}^{\prime}$ for $\mathrm{x} \in \mathrm{R}\left(\gamma, \psi, \mathrm{a}^{\prime}, \mathrm{d}^{\prime}\right)$ with $\psi(x)=\mathrm{a}^{\prime}$.

Then $\mathrm{T}$ has at least three fixed points $\mathrm{x}_{1}, \mathrm{x}_{2}, \mathrm{x}_{3} \in \overline{\mathrm{P}\left(\gamma, \mathrm{d}^{\prime}\right)}$ such that

$$
\gamma\left(x_{i}\right) \leqslant d^{\prime} \text { for } i=1,2,3 ; \quad b^{\prime}<\varphi\left(x_{1}\right) ; \quad a^{\prime}<\psi\left(x_{2}\right) \text { with } \varphi\left(x_{2}\right)<b^{\prime} ; \quad \psi\left(x_{3}\right)<a^{\prime} .
$$

\section{Main results}

Denote the operator $\mathrm{T}: \mathrm{C}^{1}[0,1] \rightarrow \mathrm{C}^{1}[0,1]$ as:

$$
T u(t):=\int_{0}^{1} G(t, s) f\left(s, u(s), u^{\prime}(s)\right) d s+\int_{0}^{1} R(t, s) \int_{0}^{1} G(s, \tau) f\left(\tau, u(\tau), u^{\prime}(\tau)\right) d \tau d s
$$

While considering the Banach space $E=\left(C^{1}[0,1],\|\cdot\|\right)$ with the maximum norm

$$
\|u\|=\max \left\{\max _{t \in[0,1]}|u(t)|, \max _{t \in[0,1]}\left|u^{\prime}(t)\right|\right\} .
$$

Define the cone $\mathrm{P} \subset \mathrm{E}$ by

$$
P=\{u \in E \mid u(t) \geqslant 0 \text { and } u(t) \text { is convex on }[0,1]\} .
$$

And denote a nonnegative continuous concave functional $\varphi$, the nonnegative continuous convex functionals $\theta, \gamma$ and the nonnegative continuous functional $\psi$ on the cone $\mathrm{P}$ as follows:

$$
\gamma(\mathfrak{u})=\max _{\mathfrak{t} \in[0,1]}\left|\mathfrak{u}^{\prime}(\mathrm{t})\right|, \quad \psi(u)=\theta(u)=\max _{\mathfrak{t} \in[0,1]}|\mathfrak{u}(\mathrm{t})|, \quad \varphi(u)=\min _{\mathfrak{t} \in[\delta, 1-\delta]}|\mathfrak{u}(\mathrm{t})| \text { for } \delta \in\left[0, \frac{1}{2}\right] .
$$


Lemma 3.1. If $\mathrm{u} \in \mathrm{P}$, then

$$
\max _{t \in[0,1]}|u(t)| \leqslant \frac{1+a}{1-\sigma_{1}-\sigma_{2}} \max _{t \in[0,1]}\left|u^{\prime}(t)\right|
$$

Proof. Since $u(t)=u(0)+\int_{0}^{t} u^{\prime}(s) d s$, we have

$$
\begin{aligned}
\max _{\mathfrak{t} \in[0,1]}|u(t)| \leqslant|u(0)|+\max _{\mathfrak{t} \in[0,1]}\left|u^{\prime}(t)\right| & \leqslant\left|-a u^{\prime}(0)+\int_{0}^{1} g_{1}(s) u(s) d s\right|+\max _{t \in[0,1]}\left|u^{\prime}(t)\right| \\
& \leqslant\left|a u^{\prime}(0)\right|+\left|\max _{t \in[0,1]} u(t) \int_{0}^{1} g_{1}(s) d s\right|+\max _{t \in[0,1]}\left|u^{\prime}(t)\right|,
\end{aligned}
$$

that is,

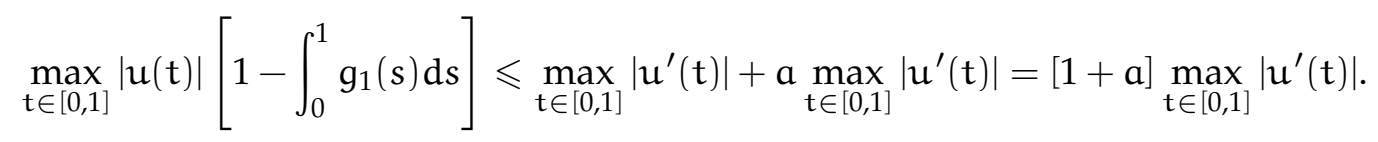

Therefore,

$$
\max _{\mathfrak{t} \in[0,1]} u(t) \leqslant \frac{1+a}{1-\sigma_{1}-\sigma_{2}} \max _{t \in[0,1]}\left|u^{\prime}(t)\right| .
$$

Lemma 3.2. For $\delta \in\left[0, \frac{1}{2}\right]$, we have $\min _{t \in[\delta, 1-\delta]} R(t, s)>\delta \max _{t \in[0,1]} R(t, s)$, where $R(t, s)$ is defined in Lemma 2.6.

Proof. From Lemma 2.6, we have

$$
\begin{aligned}
R(t, s)= & \frac{\left[\left(1-\sigma_{3}-\sigma_{4}\right) g_{1}(s)+\left(\sigma_{1}+\sigma_{2}-1\right) g_{2}(s)\right]}{(a+b-1) \rho} \cdot t \\
& +\frac{\left[a \sigma_{3}+(b-1)\left(1-\sigma_{4}\right)\right] g_{1}(s)+\left[a\left(1-\sigma_{1}\right)+(b-1) \sigma_{2}\right] g_{2}(s)}{(a+b-1) \rho}
\end{aligned}
$$

Denote

and

$$
k(s)=\frac{\left[\left(1-\sigma_{3}-\sigma_{4}\right) g_{1}(s)+\left(\sigma_{1}+\sigma_{2}-1\right) g_{2}(s)\right]}{(a+b-1) \rho},
$$

$$
d(s)=\frac{\left[a \sigma_{3}+(b-1)\left(1-\sigma_{4}\right)\right] g_{1}(s)+\left[a\left(1-\sigma_{1}\right)+(b-1) \sigma_{2}\right] g_{2}(s)}{(a+b-1) \rho}
$$

On one hand, when $k(s)<0$ with $0<\left(1-\sigma_{3}-\sigma_{4}\right) g_{1}(s)<\left(1-\sigma_{1}-\sigma_{2}\right) g_{2}$ (s), so due to monotonicity of $R(t, s)$, maximum value of $R(t, s)$ is $R(0, s)=d(s)>0$ and minimum value is $R(1, s)=k(s)+d(s)>0$. So

$$
\frac{\min _{t \in[\delta, 1-\delta]} R(t, s)}{\max _{t \in[0,1]} R(t, s)}=\frac{R(1-\delta, s)}{R(0, s)}=\frac{(1-\delta) k(s)+d(s)}{d(s)}=\frac{(1-\delta) k(s)}{d(s)}+1>\delta .
$$

When $k(s)<0$ with $\left(1-\sigma_{3}-\sigma_{4}\right) g_{1}(s)<0<\left(1-\sigma_{1}-\sigma_{2}\right) g_{2}(s)$. Minimum value of $R(t, s)$ is $R(1, s)$ and

$$
\begin{aligned}
\mathrm{R}(1, \mathrm{~s}) & =\frac{\left[(\mathrm{a}-1) \sigma_{3}+\mathrm{b}\left(1-\sigma_{4}\right)\right] \mathrm{g}_{1}(\mathrm{~s})+\left[(\mathrm{a}-1)\left(1-\sigma_{1}\right)+\mathrm{b}_{2}\right] \mathrm{g}_{2}(\mathrm{~s})}{(\mathrm{a}+\mathrm{b}-1) \rho} \\
& >\frac{\left(1-\sigma_{4}\right) g_{1}(\mathrm{~s})+\sigma_{2} \cdot \frac{1-\sigma_{3}-\sigma_{4}}{1-\sigma_{1}-\sigma_{2}} g_{1}(\mathrm{~s})}{(\mathrm{a}+\mathrm{b}-1) \rho}=\frac{\mathrm{g}_{1}(\mathrm{~s})}{\left(1-\sigma_{1}-\sigma_{2}\right)(\mathrm{a}+\mathrm{b}-1)}>0,
\end{aligned}
$$

the expression (3.1) also holds. 
On the other hand, when $k(s) \geqslant 0$, that is $\left(1-\sigma_{3}-\sigma_{4}\right) g_{1}(s) \geqslant\left(1-\sigma_{1}-\sigma_{2}\right) g_{2}(s) \geqslant 0$. Then minimum value of $R(t, s)$ is $R(0, s)>0$. So

$$
\frac{\min _{t \in[\delta, 1-\delta]} R(t, s)}{\max _{t \in[0,1]} R(t, s)}=\frac{R(\delta, s)}{R(1, s)}=\frac{\delta k(s)+d(s)}{k(s)+d(s)} \geqslant \delta .
$$

Therefore, for $\delta \in\left[0, \frac{1}{2}\right]$, we get $\min _{t \in[\delta, 1-\delta]} R(t, s)>\delta \max _{t \in[0,1]} R(t, s)$.

Lemma 3.3. If $\mathrm{u} \in \mathrm{P}, \delta \in\left[0, \frac{1}{2}\right]$, then $\min _{\mathfrak{t} \in[\delta, 1-\delta]} \mathrm{u}(\mathrm{t}) \geqslant \delta \max _{\mathfrak{t} \in[0,1]} \mathrm{u}(\mathrm{t})$ holds.

Proof. From Lemma 3.2 we have

$$
\begin{aligned}
& \min _{t \in[\delta, 1-\delta]} u(t)=\min _{t \in[\delta, 1-\delta]}\left\{\int_{0}^{1} G(t, s) y(s) d s+\int_{0}^{1} R(t, s) \int_{0}^{1} G(s, \tau) y(\tau) d \tau d s\right\} \\
& \geqslant \min _{t \in[\delta, 1-\delta]}(1-t) \int_{0}^{1} G(0, s) y(s) d s+\int_{0}^{1} \min _{t \in[\delta, 1-\delta]} R(t, s) \int_{0}^{1} G(s, \tau) y(\tau) d \tau d s \\
& \geqslant \delta \int_{0}^{1} \max _{t \in[0,1]} G(t, s) y(s) d s+\delta \int_{0}^{1} \max _{t \in[0,1]} R(t, s) \int_{0}^{1} G(s, \tau) y(\tau) d \tau d s \\
& \geqslant \delta \max _{t \in[0,1]}\left\{\int_{0}^{1} G(t, s) y(s) d s+\int_{0}^{1} R(t, s) \int_{0}^{1} G(s, \tau) y(\tau) d \tau d s\right\} \\
& =\delta \max _{t \in[0,1]} u(t) .
\end{aligned}
$$

Hence, $\min _{\mathfrak{t} \in[\delta, 1-\delta]} \mathfrak{u}(\mathrm{t}) \geqslant \delta \max _{\mathfrak{t} \in[0,1]} \mathfrak{u}(\mathrm{t})$.

Put

$$
\begin{aligned}
M_{1} & =\max \left\{\mid \frac{\partial R(t, s)}{\partial t} \| t, s \in[0,1]\right\}, & M_{2}=\max \{R(t, s) \mid t, s \in[0,1]\}, \\
K & =\frac{\alpha(a+b-1)+a M_{1}(\alpha b-1)}{(a+b-1) \Gamma(\alpha+1)}, & L=\frac{\delta a(\alpha b-1)}{(a+b-1) \Gamma(\alpha+1)} \\
N & =\left(1+M_{2}\right) \frac{a(\alpha b-1)}{(a+b-1) \Gamma(\alpha+1)} . &
\end{aligned}
$$

Theorem 3.4. Assume there exist constants $0<\mathrm{a}^{\prime}<\mathrm{b}^{\prime}<\mathrm{c}^{\prime}<\mathrm{d}^{\prime}$, where $\mathrm{c}^{\prime}=\frac{\mathrm{b}^{\prime}}{\delta}$, and suppose the function $\mathrm{f}\left(\mathrm{t}, \mathrm{u}(\mathrm{t}), \mathrm{u}^{\prime}(\mathrm{t})\right)$ satisfying the conditions:

$\left(A_{1}\right) f(t, u, v) \leqslant d^{\prime} / K$ for $(t, u, v) \in[0,1] \times\left[0, \frac{(1+a)}{1-\sigma_{1}-\sigma_{2}} d^{\prime}\right] \times\left[-d^{\prime}, d^{\prime}\right]$,

$\left(A_{2}\right) f(t, u, v) \geqslant b^{\prime} / L$ for $(t, u, v) \in[\delta, 1-\delta] \times\left[b^{\prime}, \frac{b^{\prime}}{\delta}\right] \times\left[-d^{\prime}, d^{\prime}\right]$,

$\left(\mathrm{A}_{3}\right) \mathrm{f}(\mathrm{t}, \mathrm{u}, v)<\mathrm{a}^{\prime} / \mathrm{N}$ for $(\mathrm{t}, \mathrm{u}, v) \in[0,1] \times\left[0, \mathrm{a}^{\prime}\right] \times\left[-\mathrm{d}^{\prime}, \mathrm{d}^{\prime}\right]$.

Then the boundary value problem (1.1) has at least three positive solutions $\mathrm{u}_{1}, \mathrm{u}_{2}$, and $\mathrm{u}_{3}$ satisfying

$$
\begin{aligned}
\max _{\mathrm{t} \in[0,1]}\left|\mathrm{u}_{\mathfrak{i}}^{\prime}(\mathrm{t})\right| & \leqslant \mathrm{d}^{\prime} \quad \text { for } \mathrm{i}=1,2,3, \\
\mathbf{b}^{\prime} & <\min _{\mathrm{t} \in[\delta, 1-\delta]}\left|\mathrm{u}_{1}(\mathrm{t})\right|, \\
\mathrm{a}^{\prime} & <\max _{\mathrm{t} \in[0,1]}\left|\mathrm{u}_{2}(\mathrm{t})\right| \text { with } \min _{\mathrm{t} \in[\delta, 1-\delta]}\left|\mathrm{u}_{2}(\mathrm{t})\right|<\mathrm{b}^{\prime}, \\
\max _{\mathrm{t} \in[0,1]}\left|\mathrm{u}_{3}(\mathrm{t})\right| & <\mathrm{a}^{\prime} .
\end{aligned}
$$

Proof. The BVP (1.1) has a solution $u=u(t)$ if and only if $u$ is the solution of the operator equation

$$
u=T u(t):=\int_{0}^{1} G(t, s) f\left(s, u(s), u^{\prime}(s)\right) d s+\int_{0}^{1} R(t, s) \int_{0}^{1} G(s, \tau) f\left(\tau, u(\tau), u^{\prime}(\tau)\right) d \tau d s .
$$

Since preparations are completed, we start to verify the operator $\mathrm{T}$ satisfies the conditions in the 
Avery-Peterson fixed-point theorem in order to find out main results of the problem we are discussing. If $\mathrm{u} \in \overline{\mathrm{P}\left(\gamma, \mathrm{d}^{\prime}\right)}$, then $\gamma(\mathrm{u})=\max _{\mathrm{t} \in[0,1]}\left|\mathrm{u}^{\prime}(\mathrm{t})\right| \leqslant \mathrm{d}^{\prime}$. With Lemma 3.1, we have

$$
\max _{\mathfrak{t} \in[0,1]}|\mathfrak{u}(\mathbf{t})| \leqslant \frac{1+a}{1-\sigma_{1}-\sigma_{2}} \max _{\mathfrak{t} \in[0,1]}\left|\mathfrak{u}^{\prime}(\mathbf{t})\right| \leqslant \frac{1+a}{1-\sigma_{1}-\sigma_{2}} d^{\prime} .
$$

With the condition $u \in P$ and its non-negativeness on its domain and because of $T(u) \in P$ with $T u \geqslant 0$ and $T u$ is convex on $[0,1]$, the maximum value of $\left|T u^{\prime}(t)\right|$ is either $\left|T u^{\prime}(0)\right|$ or $\left|T u^{\prime}(1)\right|$. Combining with the assumption $\left(\mathrm{A}_{1}\right)$, we have

$$
\begin{aligned}
\gamma(T u(t))= & \max _{t \in[0,1]}\left|(T u)^{\prime}(t)\right| \\
= & \max _{\{}\left\{(T u)^{\prime}(0)|,|(T u)^{\prime}(1) \mid\right\} \\
\leqslant & \left|\int_{0}^{1} \frac{[b(\alpha-1)-(1-s)](1-s)^{\alpha-2}}{(a+b-1) \Gamma(\alpha)} f\left(s, u(s), u^{\prime}(s)\right) d s\right| \\
& +\left|\int_{0}^{1} \frac{[(a-1)(\alpha-1)+(1-s)](1-s)^{\alpha-2}}{(a+b-1) \Gamma(\alpha)} f\left(s, u(s), u^{\prime}(s)\right) d s\right| \\
& +\left|\int_{0}^{1}\right| \frac{\partial R(t, s)}{\partial t}\left|\int_{0}^{1} G(s, \tau) f\left(\tau, u(\tau), u^{\prime}(\tau)\right) d \tau d s\right| \\
\leqslant & \frac{d^{\prime}}{K} \cdot \frac{\alpha b-1}{(a+b-1) \Gamma(\alpha+1)}+\frac{d^{\prime}}{K} \cdot \frac{\alpha(a-1)+1}{(a+b-1) \Gamma(\alpha+1)}+a M_{1} \cdot \frac{d^{\prime}}{K} \frac{\alpha b-1}{(a+b-1) \Gamma(\alpha+1)} \\
= & \frac{d^{\prime}}{K}\left\{\frac{\alpha(a+b-1)+a M_{1}(\alpha b-1)}{(a+b-1) \Gamma(\alpha+1)}\right\} \leqslant d^{\prime} .
\end{aligned}
$$

Therefore, $\mathrm{T}: \overline{\mathrm{P}\left(\gamma, \mathrm{d}^{\prime}\right)} \rightarrow \overline{\mathrm{P}\left(\gamma, \mathrm{d}^{\prime}\right)}$.

To confirm the condition $\left(S_{1}\right)$ of Theorem 2.11 we choose $u(t) \equiv \frac{b^{\prime}+c^{\prime}}{2}, 0 \leqslant t \leqslant 1$. So

$$
\varphi(u)=\frac{b^{\prime}+c^{\prime}}{2}>b^{\prime}, \quad \theta(u)=\frac{b^{\prime}+c^{\prime}}{2}<c^{\prime}, \quad \text { and } \gamma(u)=0<d^{\prime} .
$$

Consequently, $\left\{u \in P\left(\gamma, \theta, \varphi, b^{\prime}, c^{\prime}, d^{\prime}\right) \mid \varphi(u)>b^{\prime}\right\} \neq \Phi$. Moreover, if $u \in P\left(\gamma, \theta, \varphi, b^{\prime}, c^{\prime}, d^{\prime}\right)$, then $b^{\prime} \leqslant$ $u(t) \leqslant c^{\prime}$ and $\left|u^{\prime}(t)\right| \leqslant d^{\prime}$ hold for $t \in[\delta, 1-\delta]$.

By using the assumption $\left(\mathrm{A}_{2}\right)$, we try to check the condition $\left(\mathrm{S}_{1}\right)$ of Theorem 2.11 .

$$
\begin{aligned}
\varphi(T u(t)) & =\min _{t \in[\delta, 1-\delta]}|(T u)(t)| \\
& =\min _{t \in[\delta, 1-\delta]}\left\{\int_{0}^{1} G(t, s) f\left(s, u(s), u^{\prime}(s)\right) d s+\int_{0}^{1} R(t, s) \int_{0}^{1} G(s, \tau) f\left(\tau, u(\tau), u^{\prime}(\tau)\right) d \tau d s\right\} \\
& \geqslant \min _{t \in[\delta, 1-\delta]}\left\{(1-t) \int_{0}^{1} G(0, s) f\left(s, u(s), u^{\prime}(s)\right) d s+\int_{0}^{1}(1-s) R(t, s) \int_{0}^{1} G(0, \tau) f\left(\tau, u(\tau), u^{\prime}(\tau)\right) d \tau d s\right\} \\
& \geqslant \frac{b^{\prime}}{L} \min _{t \in[\delta, 1-\delta]}\left\{(1-t)+\int_{0}^{1}(1-s) R(t, s) d s\right\} \int_{0}^{1} G(0, s) d s \\
& \geqslant \frac{b^{\prime}}{L} \delta \int_{0}^{1} G(0, s) d s \geqslant b^{\prime} .
\end{aligned}
$$

So the condition $\left(\mathrm{S}_{1}\right)$ is satisfied.

If $u \in P\left(\gamma, \varphi, b^{\prime}, d^{\prime}\right)$ and $\theta(T u)>\frac{b^{\prime}}{\delta}$, then

$$
\varphi(T u)=\min _{t \in[\delta, 1-\delta]}(T u)(t) \geqslant \delta \max _{t \in[0,1]}(T u)(t)=\delta \theta(T u)>\delta \cdot \frac{b^{\prime}}{\delta}=b^{\prime} .
$$


So condition $\left(\mathrm{S}_{2}\right)$ of Theorem 2.11 follows.

Finally, we show that the condition $\left(\mathrm{S}_{3}\right)$ of Theorem 2.11 holds.

Clearly, $\psi(0)=0<a^{\prime}$, so $0 \notin R\left(\gamma, \psi, a^{\prime}, d^{\prime}\right)$. While $u \in R\left(\gamma, \psi, a^{\prime}, d^{\prime}\right)$ with $\psi(u)=a^{\prime}$ we have that $0 \leqslant \mathrm{u}(\mathrm{t}) \leqslant \mathrm{a}^{\prime}, \mathrm{t} \in[0,1]$. With assumption $\left(\mathrm{A}_{3}\right)$,

$$
\begin{aligned}
\psi(T u) & =\max _{t \in[0,1]}|T u(t)| \\
& =\max _{t \in[0,1]}\left|\int_{0}^{1} G(t, s) f\left(s, u(s), u^{\prime}(s)\right) d s+\int_{0}^{1} R(t, s) \int_{0}^{1} G(s, \tau) f\left(\tau, u(\tau), u^{\prime}(\tau)\right) d \tau d s\right| \\
& \leqslant \max _{t \in[0,1]}\left|\int_{0}^{1} G(0, s) f\left(s, u(s), u^{\prime}(s)\right) d s\right|+\max _{t \in[0,1]}\left|\int_{0}^{1} R(t, s) \int_{0}^{1} G(0, \tau) f\left(\tau, u(\tau), u^{\prime}(\tau)\right) d \tau d s\right| \\
& \leqslant \max _{t \in[0,1]}\left\{\left[1+\int_{0}^{1} R(t, s) d s\right] \int_{0}^{1} G(0, s) f\left(s, u(s), u^{\prime}(s)\right) d s\right\} \\
& <\left(1+M_{2}\right) \cdot \frac{a^{\prime}}{N} \int_{0}^{1} G(0, s) d s=\frac{a^{\prime}}{N}\left(1+M_{2}\right) \frac{a(\alpha b-1)}{(a+b-1) \Gamma(\alpha+1)}=a^{\prime} .
\end{aligned}
$$

Therefore, the BVP (1.1) has at least three positive solutions $u_{1}, u_{2}$, and $u_{3}$ such that

$$
\begin{aligned}
\max _{t \in[0,1]}\left|u_{i}^{\prime}(t)\right| & \leqslant d^{\prime} \text { for } i=1,2,3, \\
b^{\prime} & <\min _{t \in[\delta, 1-\delta]}\left|u_{1}(t)\right|, \\
a^{\prime} & <\max _{t \in[0,1]}\left|u_{2}(t)\right| \text { with } \min _{t \in[\delta, 1-\delta]}\left|u_{2}(t)\right|<b^{\prime}, \\
\max _{t \in[0,1]}\left|u_{3}(t)\right| & <a^{\prime} .
\end{aligned}
$$

The proof of the theorem is completed.

\section{Example}

Consider the boundary value problem:

$$
\left\{\begin{array}{l}
{ }^{c} D_{0+}^{\frac{7}{2}} u(t)=f\left(t, u(t), u^{\prime}(t)\right), \quad t \in[0,1] \\
u^{\prime \prime}(0)=0, u^{(3)}(0)=0 \\
u(0)+u^{\prime}(0)=\int_{0}^{1} s u(s) d s \\
u(1)-2 u^{\prime}(1)=\int_{0}^{1} 3 s u(s) d s
\end{array}\right.
$$

where

$$
f(t, u, v)= \begin{cases}\frac{t}{100}+\frac{u^{8}}{8}+\frac{1}{12}\left(\frac{v}{10^{4}}\right)^{3}, & 0 \leqslant u \leqslant 4, \\ \frac{t}{100}+\frac{4^{8}}{8}+\frac{1}{12}\left(\frac{v}{10^{4}}\right)^{3}, & u \geqslant 4 .\end{cases}
$$

Put $\mathrm{a}^{\prime}=1, \mathrm{~b}^{\prime}=3, \mathrm{~d}^{\prime}=10^{4}$ and $\delta=\frac{1}{6}$, by calculating, $\sigma_{1}=\frac{5}{12}, \sigma_{2}=\frac{1}{12}, \sigma_{3}=\frac{5}{4}, \sigma_{4}=\frac{1}{4}, \rho=\frac{1}{3}$, and $M_{1}=$ $3, \mathrm{M}_{2}=6, \mathrm{~m}_{1}=0$. In addition, $\mathrm{K}=\frac{40}{21 \sqrt{\pi}} \approx 1.0746468, \mathrm{~L}=\frac{8}{105 \sqrt{\pi}} \approx 0.0429857, \mathrm{~N}=\frac{16}{5 \sqrt{\pi}} \approx 1.8054067$. Then $f(t, u, v)$ satisfies

$$
\begin{aligned}
& f(t, u, v) \leqslant \frac{d^{\prime}}{K} \approx 9305.3827173 \text { for } f(t, u, v) \in[0,1] \times\left[0,4 \times 10^{4}\right] \times\left[-10^{4}, 10^{4}\right], \\
& f(t, u, v) \geqslant \frac{b^{\prime}}{L} \approx 69.7903704 \text { for } f(t, u, v) \in\left[\frac{1}{6}, \frac{5}{6}\right] \times[3,18] \times\left[-10^{4}, 10^{4}\right], \\
& f(t, u, v) \leqslant \frac{a^{\prime}}{N} \approx 0.5538918 \text { for } f(t, u, v) \in[0,1] \times[0,1] \times\left[-10^{4}, 10^{4}\right] .
\end{aligned}
$$

The proof shows that all conditions in Theorem 2.11 hold, and equation (4.1) has at least three positive solutions. 


\section{Acknowledgment}

The authors thank the referees for their careful reading of the manuscript and insightful comments, which help to improve the quality of the paper. We would also like to acknowledge the valuable comments and suggestions from the editors, which vastly contribute to the perfection of the paper.

\section{References}

[1] B. Ahmad, R. P. Agarwal, On nonlocal fractional boundary value problems, Dyn. Contin. Discrete Impuls. Syst. Ser. A Math. Anal., 18 (2011), 535-544. 1

[2] B. Ahmad, J. J. Nieto, Existence results for nonlinear boundary value problems of fractional integrodifferential equations with integral boundary conditions, Bound. value probl., 2009 (2009), 11 pages. 1

[3] R. I. Avery, A. C. Peterson, Three positive fixed points of nonlinear operators on ordered Banach spaces, Comput. Math. Appl., 42 (2001), 311-322. 2.11

[4] A. Boucherif, Second-order boundary value problems with integral boundary conditions, Nonlinear Anal., 70 (2009), 364-371. 1

[5] A. Cabada, G. Wang, Positive solutions of nonlinear fractional differential equations with integral boundary value conditions, J. Math. Anal. Appl., 389 (2012), 403-411. 1, 2.4, 2.5

[6] M. Jia, X. Liu, Three nonnegative solutions for fractional differential equtaions with integral boudary conditions, Comput. Math. Appl., 62 (2011), 1405-1412.

[7] W. Sun, Y. Wang, Multiple positive solutions of nonlinear fractional differential equations with integral boundary value conditions, Fract. Calc. Appl. Anal., 17 (2014), 605-616. 1

[8] Y. Wang, W. Ge, Multiple positive solutions for multipoint boundary value problems with one-dimensional p-Laplacian, J. Math. Anal. Appl., 327 (2007), 1381-1395. 2.8, 2.9

[9] Z. Wei, C. Pang, Y. Ding, Positive solutions of singular Caputo fractional differential equations with integral boundary conditions, Commun. Nonlinear Sci. Numer. Simulat., 17 (2012), 3148-3160. 1

[10] S. Zhang, Positive solutions for boundary value problems of linear fractional differential equations, Electr. J. Differ. Equ., 2006 (2006), 12 pages. 1

[11] L. Zhang, Existence of positive solutions for a class of fractional differential equations with integral boundary conditions, Acta. Math. Appl. Sin., 38 (2015), 423-433. 1

[12] L. Zhang, Z. Xuan, Multiple positive solutions for a second-order boundary value problem with integral boundary conditions, Bound. value probl., 2016 (2016), 8 pages. 1 